\title{
Powder and Solution for Suspension for Injection
}

National Cancer Institute

\section{Source}

National Cancer Institute. Powder and Solution for Suspension for Injection. NCI

Thesaurus. Code C162314.

Sterile powder (including freeze-dried powder) and sterile solution, both of which contain active substance(s), intended for the preparation of a suspension for injection by dispersing the powder in the solution. 